\title{
Squamous cell carcinoma of the stomach
}

INSERM

\section{Source}

INSERM. (1999). Orphanet: an online rare disease and orphan drug data base. Squamous cell carcinoma of the stomach. ORPHA:418959

Squamous cell carcinoma of stomach is a rare epithelial tumour of stomach, defined histropathologically as keratinizing cell masses with pearl formation, mosaic pattern of cell arrangement, intercellular bridges, and high concentrations of sulphydryl or disulphide bonds, arising directly from gastric mucosa, without esophageal involvement. It is characterized by preferential location in the upper third of the stomach, high probability of lymphovascular and serosal invasion and late onset of clinical symptoms associated with poor prognosis including nonspecific symptoms of abdominal pain, dysphagia, vomiting, melena or hematochezia, haematemesis and weight loss. 